\title{
Effect of Self- Learning on Awareness and attitude of Technical Nursing Institute Students toward Recognition of violence against Women
}

\author{
Huda. A.Ahmed ${ }^{1}$, Samia.E.Khaton ${ }^{2}$, Samira E. El Mezayen ${ }^{3}$ \\ ${ }^{1}$ Bachelor of Nursing, faculty of Nursing, Tanta University, ${ }^{2 .}$ Assistant professor of \\ community Health Nursing, faculty of Nursing, Tanta University, ${ }^{3 .}$ Lecturer of community \\ Health Nursing, faculty of Nursing, Tanta University
}

\begin{abstract}
Violence against women is a major public health problem, which considers one of a fundamental infringement of women's human rights. Health professionals especially nurse play a vital role in early detection and recognizing abused women. The aim of the study was to assess effect of self-learning on awareness and attitude of Technical Nursing Institute students toward recognition of violence against women. Subjects and Method: Quasiexperimental research design used in this study. The study conducted at Technical Nursing Institute affiliated to Tanta University, 315 studied students were in second year 2018/2019 agreed and participate in the entire study. Tools of study Tool I: A structure questionnaire schedule Sheet, It included two parts, Part I Socio demographic data; Part II Nursing Student's knowledge regarding overview on violence against women. Tool II: Scale for Recognizing the Signs of Violence against Women by Nurses and Midwives (SRSVAWNM) .Tool III: Health Professional's Attitudes toward Identification of Female Victims of Domestic Violence Scale. Results: Total knowledge, recognition and attitude scores of studied students were highly significant improved post self-learning than pre self-learning. Conclusion: The selflearning approach was effective and improved positively the studied student's level of awareness and attitude toward recognition of violence against women. Recommendation: integrating the courses of violence against women and how to be recognized and manage into the nursing curriculum is very important.
\end{abstract}

Key words:-Women, Violence, Nursing students, Attitude and self-learning. 


\section{Tanta Scientific Nursing Journal}

\section{Introduction}

Violence against women is a great global issue. Violence against women and girls is the focus of society. The United State department of justice 2017; defined violence against women as "A pattern of violence behavior in any relationship that is used by any person to gain or maintain power and control over women or girl" (13) Violence against women occurs in many forms as physical, emotional, psychological, financial and social violence. According to justice department in United States U.S 2019; 1 in 3 women around the world have experienced either physical and/or sexual violence, mostly by an intimate partner ${ }^{(4)}$.

According to the World Health organization (WHO) 2018, at least 37 percent of women who have been married in the Arab World region 2017-2018 have experienced physical or sexual violence by their partner ${ }^{(5,6)}$. The survey conducted by the Arab Barometer in 2018/2019, reported that, at least 60 percent of women in Egypt have experienced a form of verbal harassment, while 42 percent experienced a form of physical harassment ${ }^{(6-8)}$. Risk factors of violence against women occur initially from individual, family, community and wider society levels. Violence against women increase in low education, low income, low sanitary environment and low chance of women's employment. Violence against women also increases with beliefs and norms with gender inequality ${ }^{(8-11)}$.

Violence against women causes serious short and long-term effects not only on women but also on family, children and society. So it's important to health professionals to identify this problem well especially nurses to have adequate knowledge, skills and practice in identifying signs of violence and dealing with its victims properly. This may occur through self-learning (SL) which is an essential concept in problem-based learning (PBL); and in a broader sense, student-centered learning. Considering the complex nature of SL, it has also taken for granted and give a shallow meaning, selfstudy ${ }^{(9-10)}$.

Nurses attitude toward violence against women as an unjustifiable act, they considered their role as providing support to women and collaborating with other institutions and willing to help, but do not know how; health professional's find barriers that decrease ability in dealing with abused women; barriers appearing at the individual level, at the institutional level and on a societal level ${ }^{(12)}$.

Self-directed Learning is the ability of students or person to be self-directed in their own Learning relies heavily on 
students being responsible for it. Selflearning provide a linking well to the characteristics of adult and lifelong learners ${ }^{(13)}$.

Self- Learning also considers a responsibility that students accept to learn, it is important to perform selflearning to nursing students for its affection on their knowledge and competence in their work for exploring violence; self-learning is flexible for the time and place for learning to be undertaken $^{(14,15)}$.

Community health nurses work in a multiple healthcare setting; therefore, nurses should be prepared at the undergraduate level; for employment to be able to face challenges; problems on scientific basic; for providing safe and quality care. The responsibility of nursing education is preparing and supporting nurses so that they can successfully adjust and respond to these challenges ${ }^{(16)}$.

Self-learning considers a modern and dynamic style to medical education. Through use of information, technology could help the students to increase the quality of nursing clinical competency. In addition, self-learning may be effective in self-directed learning. ${ }^{(17,18)}$.

The aim of this study is to: - Assess effect of self-learning on awareness and attitude of Technical Nursing Institute students toward recognition of violence against women.

Research hypothesis:-Self-learning will improve the awareness and attitude of nursing students toward recognition of violence against women.

\section{Subjects and Method}

\section{Research design:-}

Quasi-experimental research design was used in this study.

\section{Setting:-}

The study conducted at Technical Nursing Institute affiliated to Tanta University.

\section{Subjects:-}

- All students who enrolled in the second year in the previous setting in the academic year 2018/2019 and agreed to participate in the study were included. Their number were 360 students,

-20 students of them shared in pilot study and

-315 students who agreed to participate in the entire study.

\section{Tools of study:-}

Three tools were used to collect the needed data.

\section{Tool I: A structure questionnaire} schedule Sheet; that developed and used by the researcher. It included two parts as follow:-

Part I: - Socio demographic data, which include data, related to age, sex, marital status, residence and family type. 
Part II: - Nursing Student's knowledge regarding overview on violence against women. It included:

- Definition, risk factors, effect of violence on women, family and community and violence prevention.

- Causes that makes woman may not be able to leave violent relationship such as fear of retribution, financial dependence on the perpetrators; religious belief, children needs, love for one's partner and isolation.

- How to deal with abused women (women exposed to violence)

For example:-Taking history, identify causes, making full or complete examination, apply first aids ,providing physical, social and economic support and making proper referral.

Score of student's knowledge was calculated as follow.

Correct answer took (1), incorrect and do not know took (0).

Total score was classified as:

Good knowledge score $\longrightarrow \geq 70 \%$ of total knowledge score.

Fair knowledge score $\longrightarrow 50-70 \%$ of total knowledge score.

Poor knowledge score $\longrightarrow<50 \%$ of total knowledge score.

Tool II: Scale for Recognizing the Signs of Violence against Women by Nurses and Midwives (SRSVAWNM): - Which used to measure the ability of studied nursing students to recognize sings of violence against women.

It was developed by Bays an -AR abaci and Karadag ${ }^{-1} 1$ (2006) ${ }^{(14)}$. It adopted by the researcher. It consisted of 31 items, which grouped in two main subscales; physical symptoms subscale (13) items and emotional symptoms subscale (18) items true answer take (one) point or false answer take (0) point.

The physical symptoms subscale: indicating violence against women, such as (scarring, bruising, swelling, fractures, burns, restrain or grip making, black eye, unusual pattern of injury, etc.).

The Emotional symptoms subscale: indicating violence against women, such as (insomnia, distractibility communication problem, anxiety, fear fullness, etc.).

Scoring System for the Scale of Recognizing the Signs of Violence against Women by Nurses \&Midwifes (SRSVAWNM)

The minimum and maximum total scale scores were 0 and 31 , respectively.

The minimum and maximum for physical symptoms was 0 and 13 , respectively for emotional symptoms they were 0 and 18 , respectively.

High scores indicate high levels of knowledge. 
The total score were classified as:

-Adequate recognition $\longrightarrow \geq 60 \%$

of total degree.

Total attitude score were classified as

-Inadequate recognition

$\%$ total degree.

Tool III: - Health Professional's

Attitudes toward Identification of

Female Victims of Domestic

Violence Scale: which used to measure

the attitude of studied nursing students

toward recognition of Female

Victims of Domestic Violence

It was developed and validated by/ Hung Than et.al (2015) ${ }^{(15)}$. It consists of questionnaire include 14 statements that cover Direct attitude toward identification of female victims of domestic violence (include two statement); Indirect attitude toward identification of female victims of violence (include 12 statement).

\section{Scoring system of attitude scale:-}

Three point Likert scale used to give response to direct and indirect attitude asAgree take 3 point, uncertain take 2 point \&Disagree take 1 point.

The Total Scoring of the Scale was done as follow:-

\begin{tabular}{|l|c|c|c|}
\hline Items & $\begin{array}{c}\text { Number } \\
\text { of question }\end{array}$ & Minimum & Maximum \\
\hline Direct & 2 & 2 & 6 \\
\hline $\begin{array}{l}\text { Indirect } \\
\text { measure }\end{array}$ & 12 & 12 & 36 \\
\hline total & 14 & 14 & 42 \\
\hline
\end{tabular}

\section{follow}

-Positive $>70 \%$ of total attitude score.

-Negative $<70 \%$ of total attitude score

\section{Method}

\section{Obtaining approvals.}

1. An official permission to conduct the study was obtained from the Dean of the Faculty of Nursing, Tanta University to the director of Nursing Technical Institute to conduct the study.

2- Official permission to conduct the study was obtained from the director of Nursing Technical Institute after explaining the purpose of the study.

\section{Developing tools.}

Tool I was developed by the researcher, tool II, and tool III adopted and translated to Arabic language. The study tools tested for content validity by a jury of five professors' expertise in the field of Community Health Nursing before conducting the study. Validity of questionnaire based on expert's opinion was calculated and found to be 0.945 .

\section{Ethical and legal considerations.}

- Student's informed consent was obtained before beginning of the study.

- Every student informed about the purpose, nature and benefits of the study at the beginning of data collection. 
- Nature of the study not caused any harm or pain to the entire sample.

- Every student has a right1 to withdraw from the study at any time.

- Confidentiality and privacy were put into consideration regarding the data collection.

- The agreement of Ethical committee in the Faculty of Nursing Tanta University was been taken to conduct the study.

\section{A Pilot study.}

A pilot study carried out on 20 students to test the tool for its clarity and organization and to determine the length time needed to collect the data from each student. The recommended modification was done and those students were excluded from the study sample.

-Reliability of the study tool was done based on pilot study using Cronbach's alpha coefficient scale.

-The total reliability for the study; tool I knowledge was 0.942 ; tool II, recognition was 0.846 ; tool III, attitudes was 0.715 .

\section{Actual study.}

Collection of data continued for about1.5 months from the mid of March to end of April 2019.

The period of data collection from each student was approximately 15 to 20 minute to complete questionnaire.

- The self-learning education applied through the following phases:
- Assessment phase: The data was collected using previously mentioned tools through meeting nursing students to collect the base line data as pretest.

- Planning phase: A self-learning booklet about violence against women, how can be recognized by the nurse, how to deal with abused woman and proper attitude that should be followed when recognizing the abused victims was prepared by the researcher based on results of pretest assessment and literature review.

- Implementation phase: The booklet was distributed to all students to maintain self-learning about violence against woman. The researcher after two weeks meets the students in a definite time to conduct a group discussion about the content of the booklet for any clarification or misunderstanding.

- Evaluation phase: This phase is to evaluate the effectiveness of selflearning on awareness and attitude of the nursing students toward recognizing of violence against woman.

\section{Evaluation was done through two times} as follow:-

○ First time (pre-test): Before introducing self-learning booklet for the students using tool I, II and III. 
o Second time (post-test): One month after introducing self-learning booklet using tool (I) part 2, tool II and tool III.

\section{Statistical analysis}

The collected data was organized, tabulated and statistically analyzed using SPSS software statistical computer package version 20. For qualitative data chi square test $\left(\mathrm{X}^{2}\right)$ and paired sample $\mathrm{t}$ test were used. For quantitative data the range, mean, stander deviation, and comparison between more than two means. Correlation between variables was evaluated using Pearson's correlation coefficient. Significance was adopted at $\mathrm{P}<0.05$ for interpretation of results of tests of significance

\section{ResultsPart (1): Socio-demographic characteristics of studied students and their parents.}

Table (I): represents the distribution of studied students according to their sociodemographic characteristics, It shows that, the age of studied students ranged from 1822 years, with a mean $20.128+0.730$ years. Slightly less than two thirds $(62.22 \%)$ of the studied students are females. In relation to residence, about three quarters $(74.29 \%)$ of them are living in rural area.

As regards to the marital status, the most (92.06\%) of studied students were single. Also, the most of the studied students $(95.24 \%)$ live with their family. Only less than two thirds $(61.90 \%)$ of studied students have family that composed of 5-7 members. Regarding family income, less than three quarters $(70.16 \%)$ of studied students reported that they have sufficient income. The table also shows that about three quarters $(76.51 \%)$ of studied students are living with nuclear family.

Figure (1): represents the distribution of the studied student's regarding their total knowledge score toward violence against women pre and post self-learning. The figure shows that, there was only (15. $56 \%$ ) of the studied students had good knowledge score before self-learning. This percent increased to $(86.98 \%)$ post selflearning. There was a significant improvement in the total knowledge score post self-learning than pre self-learning.

Table (2): Represents the distribution of the studied student's regarding their recognition to the physical symptoms that may indicate to violence against women pre and post self-learning. It shows that, there was a significant improvement in the knowledge of studied students regarding their recognition to the physical symptoms that may indicate occurrence of violence against women Post self-learning than pre self-learning; the difference was highly significant $\mathrm{P}$-value $<0.001$.

Table (3): represents the distribution of the studied student's regarding their recognition to emotional symptoms that may indicate to violence against women pre and post self-learning. It shows that, there was a significant improvement in the 


\section{Tanta Scientific Nursing Journal}

knowledge of studied students regarding their recognition to emotional symptoms that may indicate occurrence of violence against women Post self-learning than pre self-learning; the difference was highly significant $\mathrm{P}$-value $<0.001$.

Figure (2): represents the distribution of the studied student's regarding their total recognition score toward violence against women pre and post self-learning. The figure shows that, there was only $(22.54 \%)$ of studied students had adequate recognition before self-learning. This percent increased to $(85.08 \%)$ post selflearning. There was a significant improvement in total recognition score post self-learning than pre self-learning.

Table (4): represents the distribution of the studied student's regarding direct and indirect attitude toward identification of female victims of domestic violence pre and post self-learning. It shows that, there was a significant improvement in the direct and indirect attitude toward identification of female victims of domestic violence post self-learning than pre self-learning; the difference was highly significant $\mathrm{P}$ value $<0.001$.

Figure (3): represents the distribution of the studied student's regarding their total attitude score toward identification of violence against women pre and post selflearning. The figure shows that, there was only $(87.94 \%)$ of studied students had positive attitude score before self-learning. This percent increased to $(98.10 \%)$ post self-learning. There was a significant improvement in total attitude score post self-learning than pre self-learning.

Table (5): Represents mean differences of total knowledge, recognition and attitude toward violence against women pre and post self-learning. The table shows that, the mean of total knowledge of the studied students regarding violence against woman had increased from $(27.60 \pm 10.477)$ pre self-learning to $(46.660 \pm 7.846)$ post selflearning. The table also shows that, the mean of total recognition of the studied students regarding violence against woman had increased from $(14.019 \pm 6.809)$ pre self-learning to $(25.238 \pm 5.784)$ post selflearning. As regard to the mean of total attitude of the studied students regarding violence against woman had increased from $(33.959 \pm 3.959)$ pre self-learning to (38.730 \pm 3.688$)$ post self-learning. The mean differences for knowledge, recognition and attitude were highly significant P-value $<0.001$.

Table (6): Represents the correlation between total score of students' knowledge, recognition and attitude toward violence against women pre and post self-learning. It shows that, there was a highly positive correlation between total knowledge score and the total recognition and attitude score pre and post self-learning. The table show also that, there was a highly positive correlation found between total recognition and attitude scores pre and post selflearning P-value $<0.001$. 
Table (1): Distribution of the studied students according to their socio- demographic data

Variables

Studied students $(\mathbf{N}=315)$

\begin{tabular}{|c|c|c|c|}
\hline \multirow{2}{*}{ Age } & Range & 19 & 22 \\
\hline & Mean \pm SD & 20.133 & \pm 0.718 \\
\hline & & $\mathbf{N}$ & $\%$ \\
\hline \multirow{2}{*}{ Sex } & Male & 119 & 37.78 \\
\hline & Female & 196 & 62.22 \\
\hline \multirow{2}{*}{ Residence } & City & 81 & 25.71 \\
\hline & Village & 234 & 74.29 \\
\hline \multirow{2}{*}{ Marital state } & Single & 290 & 92.06 \\
\hline & Married & 25 & 7.94 \\
\hline \multirow{3}{*}{$\begin{array}{l}\text { With whom you currently } \\
\text { reside }\end{array}$} & With family & 300 & 95.24 \\
\hline & With relatives & 3 & 0.95 \\
\hline & Other mentions & 12 & 3.81 \\
\hline \multirow{3}{*}{ Number of family members } & (2-4) Members & 105 & 33.33 \\
\hline & (5-7) Members & 195 & 61.91 \\
\hline & (8and more) Members & 15 & 4.76 \\
\hline \multirow{3}{*}{ Family income } & Sufficient & 221 & 70.16 \\
\hline & Insufficient & 75 & 23.81 \\
\hline & $\begin{array}{l}\text { Sufficient and save } \\
\text { from it }\end{array}$ & 19 & 6.03 \\
\hline \multirow[b]{2}{*}{ Family type } & Nuclear family & 241 & 76.51 \\
\hline & Extended family & 74 & 23.49 \\
\hline
\end{tabular}




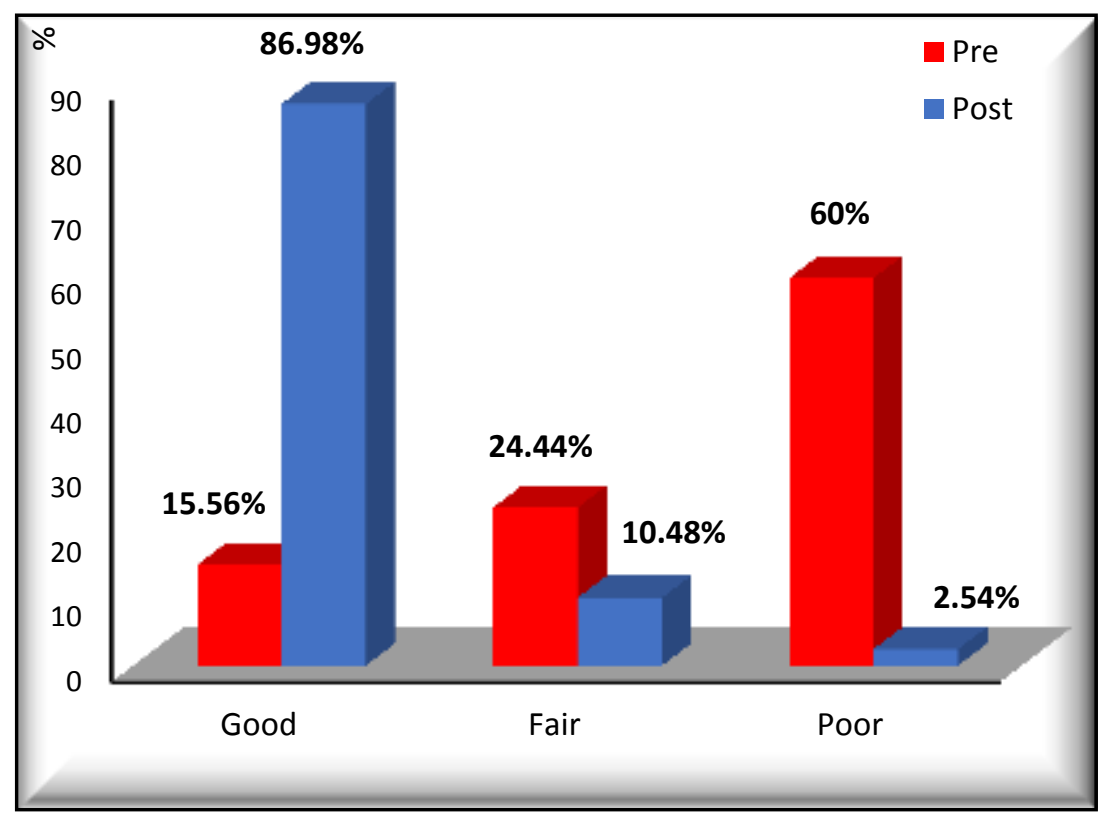

Table (2): Distribution of the studied student's regarding; their recognition to the physical symptoms that may indicate to violence against women

\begin{tabular}{|l|c|c|c|c|c|}
\hline \multirow{2}{*}{$\begin{array}{l}\text { Physical symptoms indicate violence against } \\
\text { women. It include }\end{array}$} & N & $\%$ & N & $\%$ & $\begin{array}{c}\text { X } \\
\text { P-value }\end{array}$ \\
\hline Scarring & 215 & 68.25 & 302 & 95.87 & $\begin{array}{c}81.623 \\
<0.001^{*}\end{array}$ \\
\hline Bruising & 232 & 73.65 & 300 & 95.24 & $\begin{array}{c}55.875 \\
<0.001^{*}\end{array}$ \\
\hline Fractures & 233 & 73.97 & 306 & 97.14 & $\begin{array}{c}68.447 \\
<0.001^{*}\end{array}$ \\
\hline Burns & 98 & 31.11 & 213 & 67.62 & $\begin{array}{c}83.982 \\
<0.001^{*}\end{array}$ \\
\hline Scratches & 154 & 48.89 & 269 & 85.40 & $\begin{array}{c}95.154 \\
<0.001^{*}\end{array}$ \\
\hline Black eye. & 113 & 35.87 & 218 & 69.21 & $\begin{array}{c}70.181 \\
<0.001^{*}\end{array}$ \\
\hline Restrain or grip making. & 159 & 50.48 & 284 & 90.16 & $\begin{array}{c}118.827 \\
<0.001^{*}\end{array}$ \\
\hline Chronic headache, fatigue. & 102 & 32.38 & 232 & 73.65 & $\begin{array}{c}107.693 \\
<0.001^{*}\end{array}$ \\
\hline Unwanted pregnancy. & 100 & 31.75 & 269 & 85.40 & $\begin{array}{c}186.830 \\
<0.001^{*}\end{array}$ \\
\hline Urinary tract infection. & 58 & 18.41 & 234 & 74.29 & $\begin{array}{c}197.727 \\
<0.001^{*}\end{array}$ \\
\hline Pelvic or /and Vaginal pain. & 92 & 29.21 & 225 & 71.43 & $\begin{array}{c}112.316 \\
<0.001^{*}\end{array}$ \\
\hline Swelling & 127 & 40.32 & 241 & 76.51 & $\begin{array}{c}84.918 \\
<0.001^{*}\end{array}$ \\
\hline Criminal wound (with gun -knife ...) & 207 & 65.71 & 303 & 96.19 & $\begin{array}{c}94.871 \\
<0.001^{*}\end{array}$ \\
\hline
\end{tabular}

Highly significant P-value $<0.001$ 
Table (3): Distribution of the studied student's regarding; their recognition to emotional symptoms that may indicate to violence against women pre and post self-learning

\begin{tabular}{|c|c|c|c|c|c|}
\hline \multirow{2}{*}{$\begin{array}{l}\text { Emotional symptoms indicate } \\
\text { violence against women. It include }\end{array}$} & \multicolumn{2}{|c|}{ Pre } & \multicolumn{2}{|c|}{ Post } & \multirow[b]{2}{*}{$\begin{array}{c}\mathrm{X}^{2} \\
\text { P-value }\end{array}$} \\
\hline & $\mathbf{N}$ & $\%$ & $\mathbf{N}$ & $\%$ & \\
\hline Fear fullness. & 209 & 66.35 & 283 & 89.84 & $\begin{array}{c}50.811 \\
<0.001 *\end{array}$ \\
\hline Anxiety & 170 & 53.97 & 254 & 80.63 & $\begin{array}{c}50.894 \\
<0.001^{*}\end{array}$ \\
\hline Crying, sulking or temper tantrums. & 196 & 62.22 & 294 & 93.33 & $\begin{array}{c}88.200 \\
<0.001^{*}\end{array}$ \\
\hline $\begin{array}{l}\text { Excessive absenteeism on work and } \\
\text { late at bringing. }\end{array}$ & 112 & 35.56 & 232 & 73.65 & $\begin{array}{c}92.210 \\
<0.001 * \\
\end{array}$ \\
\hline Insomnia & 132 & 41.90 & 213 & 67.62 & $\begin{array}{c}42.038 \\
<0.001 * \\
\end{array}$ \\
\hline Distractibility & 125 & 39.68 & 255 & 80.95 & $\begin{array}{l}112.074 \\
<0.001 *\end{array}$ \\
\hline Increase mistakes or error. & 113 & 35.87 & 267 & 84.76 & $\begin{array}{l}157.275 \\
<0.001^{*}\end{array}$ \\
\hline Swearing or emotional language. & 118 & 37.46 & 257 & 81.59 & $\begin{array}{l}127.291 \\
<0.001 *\end{array}$ \\
\hline Forgetful and confusion & 84 & 26.67 & 207 & 65.71 & $\begin{array}{c}96.618 \\
<0.001^{*}\end{array}$ \\
\hline Inability to focus & 127 & 40.32 & 248 & 78.73 & $\begin{array}{c}96.458 \\
<0.001^{*}\end{array}$ \\
\hline Poor personal hygiene & 139 & 44.13 & 274 & 86.98 & $\begin{array}{l}128.115 \\
<0.001 *\end{array}$ \\
\hline $\begin{array}{l}\text { Sudden or unpredictable change in } \\
\text { energy level }\end{array}$ & 88 & 27.94 & 233 & 73.97 & $\begin{array}{l}133.541 \\
<0.001 *\end{array}$ \\
\hline Making inappropriate statements & 83 & 26.35 & 225 & 71.43 & $\begin{array}{r}128.089 \\
<0.001 * \\
\end{array}$ \\
\hline Low self -esteem & 141 & 44.76 & 253 & 80.32 & $\begin{aligned} & 84.990 \\
&<0.001 *\end{aligned}$ \\
\hline Loss interest in daily activities & 121 & 38.41 & 264 & 83.81 & $\begin{array}{l}136.580 \\
<0.001^{*}\end{array}$ \\
\hline Talking about attempting suicide & 216 & 68.57 & 283 & 89.84 & $\begin{array}{c}43.263 \\
<0.001 *\end{array}$ \\
\hline Abuse of alcohol or other drugs & 93 & 29.52 & 207 & 65.71 & $\begin{array}{c}82.702 \\
<0.001 *\end{array}$ \\
\hline Depression & 259 & 82.22 & 305 & 96.83 & $\begin{array}{c}35.812 \\
<0.001 *\end{array}$ \\
\hline
\end{tabular}

- Highly significant P-value $<0.001^{*}$ 


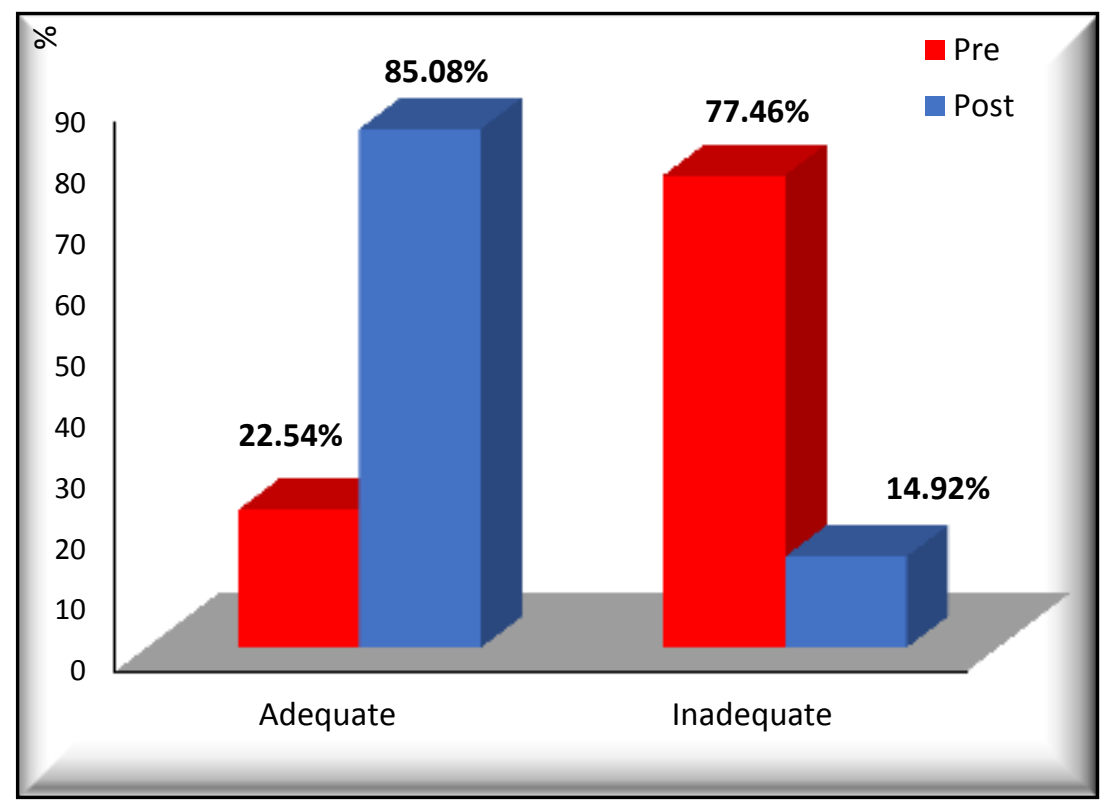

Figure (2): Distribution of the studied student's according to their total recognition score regarding violence against women pre and post self-learning. 
Table (4): Distribution of the studied student's regarding their direct and indirect attitude toward identification of female victims of domestic violence pre and post selflearning

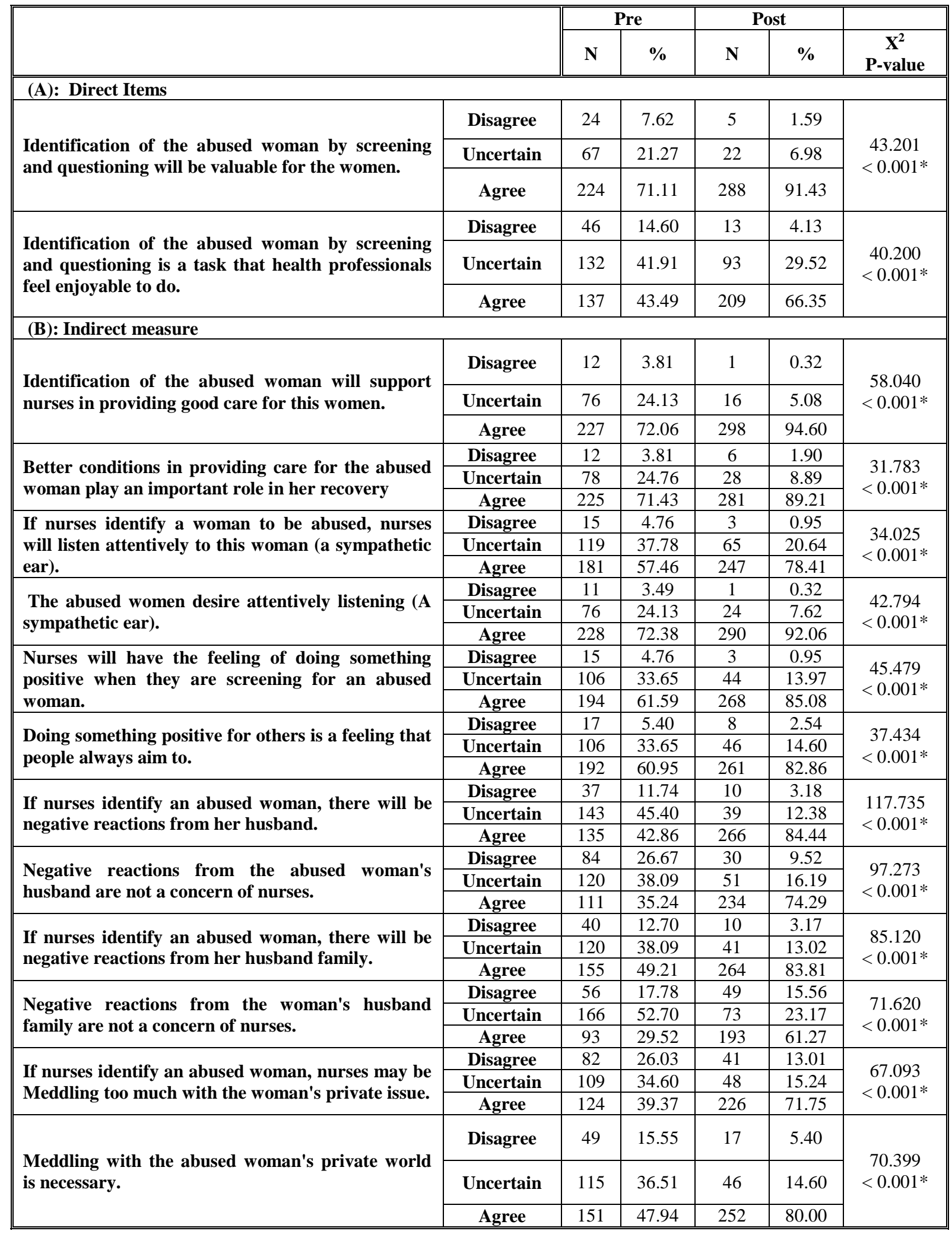

Highly significant $\mathrm{P}$-value $<0.001^{*}$ 


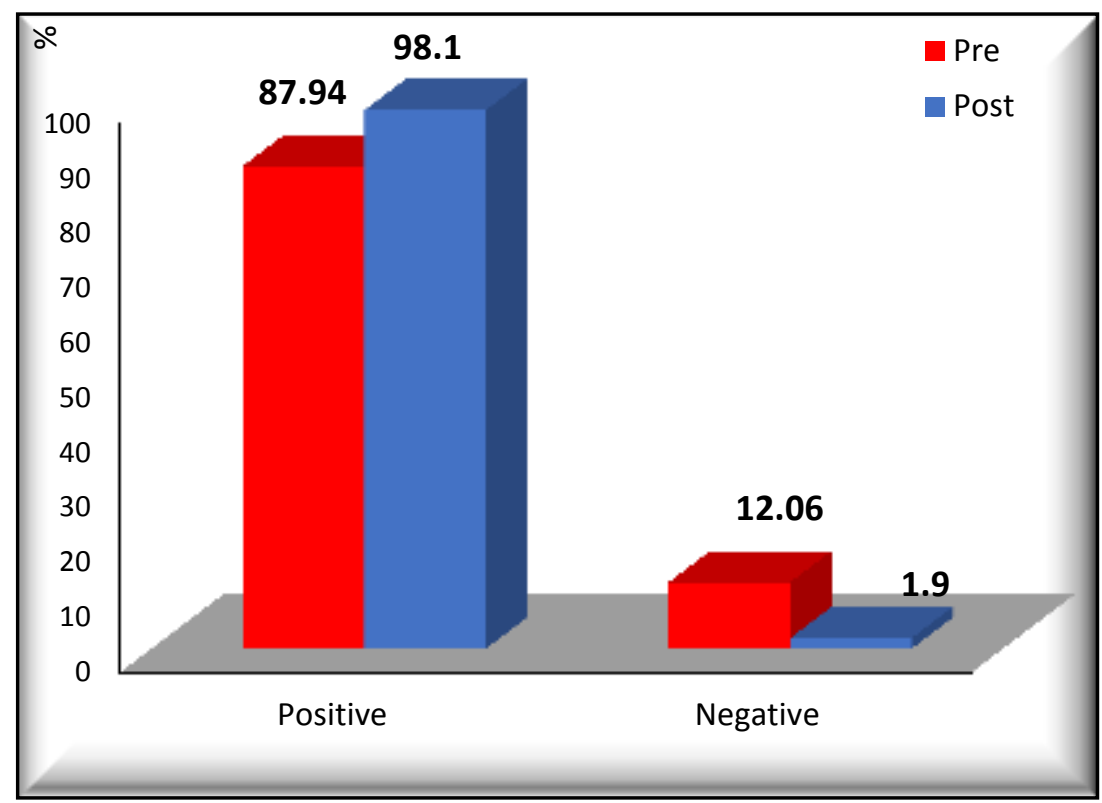

Figure (3): Distribution of the studied student's according to their total attitude score regarding violence against women pre and post self-learning

Table (5): Mean difference of total knowledge, recognition and attitude toward violence against violence pre and post self-learning.

\begin{tabular}{|l||ccc|ccc|c|c|c|c|}
\hline \multirow{2}{*}{ Variables } & \multicolumn{3}{|c|}{ Pre } & \multicolumn{3}{|c|}{ Post } & \multicolumn{2}{c|}{ Differences } & \multicolumn{2}{c|}{ Paired Test } \\
\cline { 2 - 11 } & Mean & \pm & SD & Mean & \pm & SD & Mean & SD & t & P-value \\
\hline \hline Knowledge & 27.600 & \pm & 10.477 & 46.660 & \pm & 7.864 & -19.060 & 12.921 & -26.180 & $<0.001^{*}$ \\
\hline & & & & & & & & & & \\
Recognition & 14.019 & \pm & 6.809 & 25.238 & \pm & 5.784 & -11.219 & 9.055 & -21.990 & $<0.001^{*}$ \\
\hline Attitudes & 33.959 & \pm & 3.959 & 38.730 & \pm & 3.688 & -4.771 & 5.460 & -15.509 & $<0.001^{*}$ \\
\hline
\end{tabular}

- Highly significant P-value $<0.001^{*}$ 
Table (6): correlation between total score of students' knowledge, total score of students' recognition and total score of their attitude toward violence against violence.

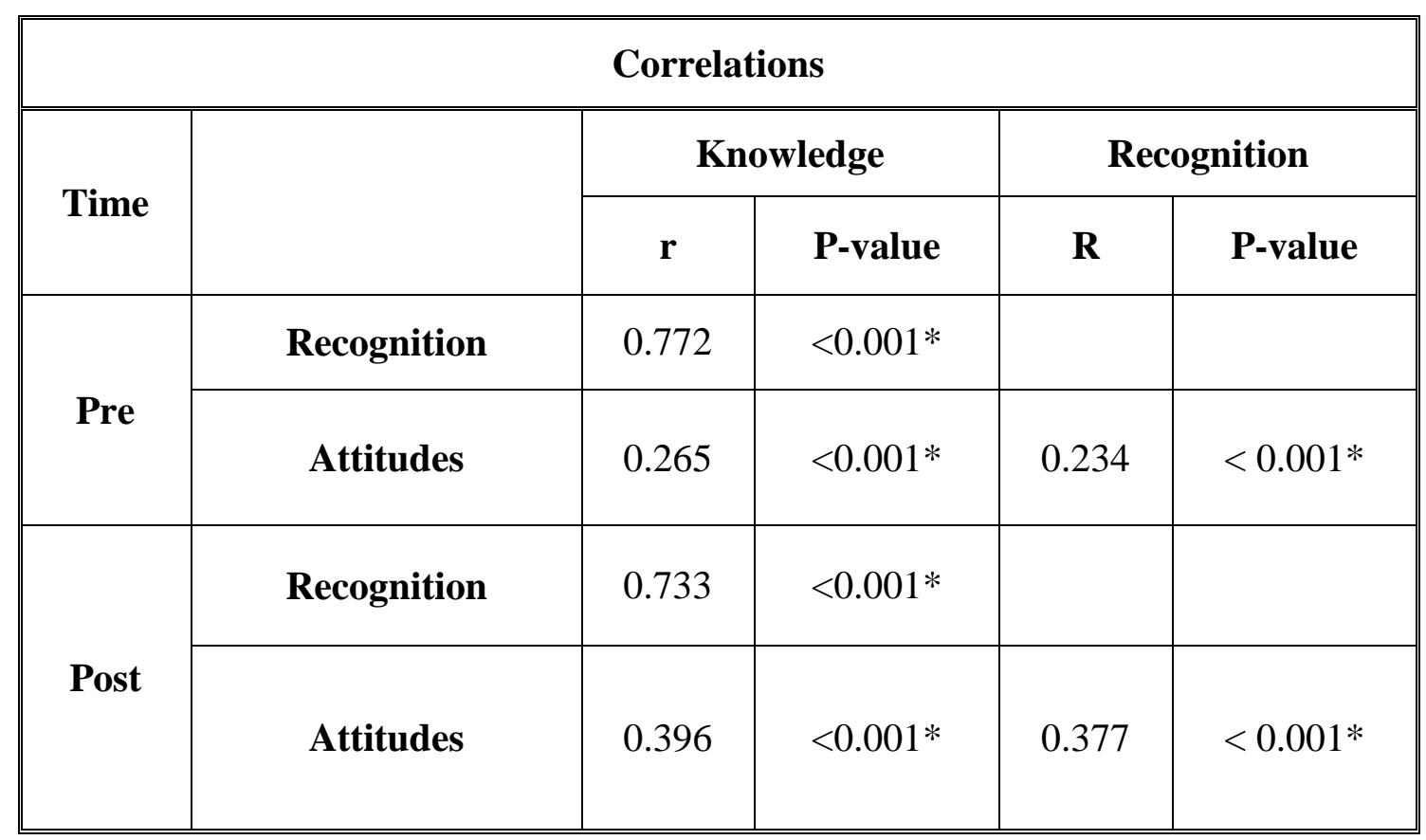

- Highly significant $\mathrm{P}$-value $<0.001^{*}$ 


\section{Tanta Scientific Nursing Journal}

\section{Discussion}

Violence is most commonly experienced in the family environment globally (EIGE, 2017) ${ }^{(19)}$. Health professional's especially nurses have a vital role in early detection of signs of violence against women, early prevention and proper management. Therefore, the aim of the study is to determine effect of self- learning on awareness and attitude of technical nursing institute students toward recognition of violence against women. Regarding sociodemographic characteristics of studied students; the result of this study revealed that the mean age of studied students were $20.128+0.730$ years; slightly less than two thirds of the studied students are females table (1). This is agreement with Sis Çelik A, Aydın A. (2019), who conduct their study on student midwives and nurses in the faculty of health sciences in northeastern Turkey and reported that, the age of students in the experimental group was $20.79 \pm 1.06$ and $60.3 \%$ of studied students were female ${ }^{(20)}$. The present study revealed that, about three quarters of the studied students are living in rural area and are living with nuclear family table (1). This disagreed with the study result of Tambağ H, Turan Z (2015), who evaluated the ability of nursing students in a Turkish school of health science to recognize signs of violence against women. He found that, the commonest longest place of residence of the students was cities. However, he reported that, the majority $(84.2 \%)$ of them came from nuclear families ${ }^{(21)}$.

The current study results showed that, there was a highly significant improvement in the ability of studied students regarding their recognition to the physical and emotional symptoms after self- learning table $(2,3)$. This related to recognizable improvement in knowledge that able studied students in recognition of violence symptoms (physical and emotional). This agreement with kyüz $\mathrm{P}$, Kahyaoğlu süt $\mathrm{H}$ (2016), who studied nurses' knowledge levels about recognition signs of violence against women, and reported that, nursing students who had received training on violence against women or who had sufficient knowledge of violence were better able to recognize the signs of violence ${ }^{(22)}$.This result also agree with Satoshi Yamagunci (2019), which his study was mental health literacy programs for school teachers, he reported that, most of the studies have significant improvement of knowledge, attitudes, behavior and/or confidence post $\operatorname{program}^{(23)}$.

On the other hand the result of the present study is contradicting with the findings of Tambağ and Turan Z. (2015), who 


\section{Tanta Scientific Nursing Journal}

reported that, students' abilities to recognize signs of violence were insufficient posttest ${ }^{(21)}$.

Sabancioğulları et al, (2016), reported that, the students wanted to receive training and have more knowledge relevant to violence against women ${ }^{(24)}$.This result disagree with the present study because they found students need advanced academic training to increase students' awareness of the issue and contributed to an increased ability to recognize signs of violence against women. Result of the present study found self-learning program able gave student nurses sufficient knowledge to recognize the signs of violence.

Regarding the improvement in the direct and indirect attitude, the result of the present study revealed that, there was a highly significant improvement in the direct and indirect attitude toward identification of female victims of domestic violence post self-learning than pre self-learning table (4).The study revealed that, there were positive reactions in direct and indirect attitude post selflearning than pre self-learning which indicate the importance of self-learning in changing attitude for nursing students toward identification of violence against women.

This result agreement with Huong NT (2015), who demonstrated that, the direct and indirect measures were positively, improved post intervention ${ }^{(25)}$. This result also agreement with McCarthy M, Bates C, (2019), who reported that, the majority of professionals in his study reported a good response when supporting a woman to report domestic violence to the Police ${ }^{(26)}$. Choudhary HA, Ali RA, (2015), reported also that health education programs (knowledge and recognition) had been effective in changing attitudes ${ }^{(27)}$. On the other hand the result of the present study is differs with the McCarthy et al, (2017), who reported that, the professionals may not be aware of what the women themselves consider to be a good response ${ }^{(28)}$. Also McLindon E, (2019), reported that, the health professionals with training and experience had more sensitive attitudes than having accessed information on violence against women ${ }^{(29)}$.The researcher result of this study found selflearning positive effect, which knowledge and recognition without stress or pressure help nurses to love learn by themselves.

Through result of the present study, there was a highly significant improvement in the total knowledge, recognition and attitude scores post self-learning than pre self-learning figure (1-3). This is agreement with Tambağ and TuranTambağ H; Turan Z. (2015), who reported that, their studied nurses had high knowledge 


\section{Tanta Scientific Nursing Journal}

score after intervention ${ }^{(21)}$. The result also agreement with Mohammed HA, (2019), who found that, there was a significant improving in nursing students' knowledge post-test than pretest ${ }^{(30)}$. The present study revealed also that, the mean differences of knowledge, recognition and attitude were highly significant improvement post selflearning than pre self-learning, table (5).This is agreement with Vakily $M$, Noroozi M, (2017), who reported that, the mean scores of awareness and attitude were increased after the intervention in both groups in comparison to before the intervention $^{(31)}$.

The result also is agreement with Jayatilleke et al, (2015), in Sri Lanka, who reported an increase in awareness score after group training ${ }^{(32)}$. Another study done by Papadakaki et al,(2013), in Greece is agreed with the present study results that, he concluded that, students' and physicians' knowledge and understanding after group training were increased ${ }^{(33)}$.

The result of the present study showed that, there was a highly positive correlation found between total recognition and attitude scores pre and post self-learning table (6).The result of present study indicated that, pro per recognition of signs and symptoms on abused women, affects positively on nurse's attitude toward this recognition and may help them to manage victims properly.

This agrees with Mahgoub E, Nimir M, (2019), in Sudan who reported that, the difference between pre-and postintervention scores of both knowledge and attitude were statistically significant improved ${ }^{(34)}$. On the other hand, the result of the study disagree with Pinar, Sukran Ertekin (2019), who reported that, significant negative correlation was found between scale for attitudes toward violence (SATV) and total mean scores of ability of nurses and midwives to recognize the signs of violence against women Scale (NMRVAWS) ${ }^{(35)}$ The researcher in his study found Students have a contemporary attitude towards violence against women can recognize signs of violence "partially sufficient". As the traditional attitude towards violence increases, the recognition of the signs of violence decreases. In the present study result, the researcher showed that, there were no significant relations found between students' knowledge score and items of socio demographic data (Residence, Marital state, Reside, Family number, Family income and Family type). The present study found that, self-learning has positive effect on knowledge score regardless to socio demographic data 
which permit and encourage learning for nurses without limitation.

\section{Conclusion}

Based on the findings of the present study, it can be concluded that; the self-learning was effective and improving the studied student's level of awareness and attitude toward recognition of violence against women. A significant improvement in knowledge score of studied students about violence against women was observed from pre and one month post self-learning; also there were a significant improvement in Recognition score and attitude score pre and one month after post self-learning. There were no significant relations found between students' knowledge, recognition and attitude score and their socio demographic data pre self-learning.

\section{Recommendation}

Related to the finding of the study the following recommendations are suggested:-

I- Integrating the courses of violence against women into the nursing curriculum to aid detection of signs of violence against women.

II- School based programs to address gender norms and attitudes, how to recognize violence against women and how to deal with it, should be provided to nursing students.
III- Provide protocols and officially distributed information on how to effectively manage abused women.

IV- Routine screening for women suffering domestic violence as a standard of care.

V- Sharing efforts of health professionals with the police, social workers, and non-governmental resources in the community toward violence against women.

\section{References}

1. Stansfield R, Williams KR. Coercive control between intimate partners: An application to nonfatal strangulation. Journal of interpersonal violence. 2018 Aug 30:0886260518795175.

2. Maurer F and Smith C; community health nursing practice, health for families and populations, 5th Ed; Saunders, an imprint of Elsevier Inc.; 2013, chapter 23, p584-593.

3. Women UN. Facts and figures: Ending violence against women. February, viewed. 2016 May; 28. Available at https://www.unwomen.org/en/what-

we-do/ending-violence-againstwomen/facts-and-figures.

4. United nation (UN) Women. International day for elimination of violence against women; 24 November 2019.Human Rights 
available at https://news.un.org/ en/story/2019/11/1052041

5. Elghossain T, Bott S, Akik C, Obermeyer CM. Prevalence of intimate partner violence against women in the Arab world: a systematic review. BMC international health and human rights. 2019 Dec 1; 19(1):29.

6. Dimitrova-Stull A. Violence against women in the EU, State of play. Briefing, European Parliamentary Research Service, 130528REV2. 2014.

7. WHO, Department of Reproductive Health and Research, London School of Hygiene and Tropical Medicine, South African Medical Research Council; Global and regional estimates of violence against women; Prevalence and health effects of intimate partner violence and nonpartner sexual violence; 2017; Number of pages, 51.at https://www.who.int/ reproductivehealth/publications/ violence/en/

8. Eltigani $\mathrm{N}$, United nations, prevalent forms of violence against women in Arab world, 2019. Available at https://infotimes.org/three-prevalentforms-of-violence-against-women.

9. Michau, Lori, MA, Horn, Jessica, MSc, Bank and Amy BA; forms, risk of violence, the lancet Dutt, Mallika, JD; Zimmerman, Cathy; Published April 25, 2015, Volume 385, Issue 9978. Pages 1672-1684.

10.World Health Organization. Regional action plan for violence and injury prevention in the Western Pacific: 2016-2020.at https://apps.who.int/iris/rest/bitstreams /1247309/retrieve.

11.John Leddo, Bhavya Boddu, The effectiveness of self-directed learning vs. teacher-led learning on gifted and talented vs. non-gifted and talented students, international Journal of Advanced Educational Research; November 2017; Volume 2; Issue 6; Page No. 18-21.

12.European Union Agency for Fundamental Rights. Violence against women: an EU-wide survey Main results [Internet]. Luxemburg: Publications Office of the European Union, 2014 [acesso 5 abril 2018]. Disponível em: http://goo.gl/1gLsv3.

13. Connell T, Barnett B and Waters D. Barriers to antenatal psychosocial assessment and depression screening in private hospital settings. Women and Birth. 2018 Aug 1; 31(4):292-8.

14.Swift HJ, Abrams D, Lamont RA and Drury L. The risks of ageism model: How ageism and negative attitudes 
toward age can be a barrier to active aging. Social Issues and Policy Review. 2017 Jan; 11(1):195-231.

15.Alshammari KF, McGarry Jand Higginbottom GM. Nurse education and understanding related to domestic violence and abuse against women: An integrative review of the literature. Nursing open. 2018 Jul;5(3):237-53.

16.Hawkins MW. Self-directed learning as related to learning strategies, selfregulation, and autonomy in an English language program: A local application with global implications. Studies in Second Language Learning and Teaching. 2018; 8(2):445-69.

17.Lemmetty S, Collin K. Self-Directed Learning as a Practice of Workplace Learning: Interpretative Repertoires of Self-Directed Learning in ICT Work. Vocations and Learning. 2019:1-24.

18.Zhoc KC and Chen G. Reliability and validity evidence for the Self-Directed Learning Scale (SDLS). Learning and Individual Differences. 2016 Jul 1; 49:245-50.

19.Trias Prats R. Women students' experiences of sexual harassment and gender-based violence in higher education in the United Kingdom visà-vis SDG 5 on gender equality,2017.

20.Sis Çelik A, Aydın A. The effect of a course on violence against women on the attitudes of student midwives and nurses towards domestic violence against women, their occupational roles in addressing violence, and their abilities to recognize the signs of violence. Perspectives in psychiatric care. 2019 Apr; 55(2):210-7.

21.Tambağ H, Turan Z. Ability of nursing students to recognize signs of violence against women. International journal of nursing knowledge. 2015 Jul; 26(3):107-12.

22.Akyüz $P$, Kahyaoğlu süt $H$. Nurses and midwives' knowledge levels about recognition s1gns of violence against women. Int Refereed J Gynaecol Dis Matern Child Health. 2016; 6:1- 15.

23. Yamaguchi S, Foo JC, Nishida A, Ogawa S, Togo F, Sasaki T. Mental health literacy programs for school teachers: A systematic review and narrative synthesis. Early Intervention in Psychiatry. 2020 Feb; 14(1):1425. https://doi.org/10.17367/JACSD.2 0166194.

24.Yilmaz FT, Sabancıoğulları S, Kumsar AK. Motivation in the first year of nursing education: It's relationship with professional self-concept, selfesteem'. Archives of Nursing Practice and Care. 2016; 2(1):50-6.

25. Karabulutlu Ö. Experiences and attitudes of nursing students regarding 
domestic violence against women. Cumhuriyet Nurse J.2015; 4(1):27- 34.

26. McCarthy M, Bates C, Triantafy P, Hunt S, Milne Skillman K. "Put bluntly, they are targeted by the worst creeps society has to offer": Police and professionals' views and actions relating to domestic violence and women with intellectual disabilities. Journal of applied research in intellectual disabilities. 2019 Jan; 32(1):71-81.

27. Choudhary HA, Ali RA, Altaf S. Knowledge, behavior and attitudes regarding HIV/AIDS among undergraduate students in an Irish university. International Journal of Surgery and Medicine. 2015; 1(2):5866.

28. McCarthy M, Hunt S, and MilneSkillman K. 'I know it was every week, but I can't be sure if it was every day: Domestic violence and women with learning disabilities. Journal of applied research in intellectual disabilities. 2017 Mar; 30(2):269-82.

29.McLindon E, Humphreys C, Hegarty $\mathrm{K}$. Is a clinician's personal history of domestic violence associated with their clinical care of patients: a crosssectional study. BMJ open. 2019 Jul 1; 9(7).

30. Mohammed HA, Farag AA. Effect of self-instructional module on knowledge and practice of nursing students regarding tube feeding insertion. Journal of Health, Medicine and Nursing. 2019 Jan 1; 4(1):1-4.

31. Vakily M, Noroozi M, Yamani N. Comparing the effect of group-based and compact disk-based training on midwives' knowledge and attitude toward domestic violence in women of reproductive age. Journal of education and health promotion. 2017; 6 .

32. Jayatilleke AC, Yoshikawa K, Yasuoka J, Poudel KC, Fernando N, Jayatilleke AU, Jimba M. Training Sri Lankan public health midwives on intimate partner violence: a pre-and post-intervention study. BMC public health. 2015 Dec 1; 15(1):331.

33. Papadakaki M, Petridou E, Kogevinas $\mathrm{M}$, Lionis C. Measuring the effectiveness of an intensive IPV training program offered to Greek general practitioners and residents of general practice. BMC medical education. 2013 Dec 1; 13(1):46.

34.Mahgoub E, Nimir M, Abdalla S and Elhuda DA. Effects of school-based health education on attitudes of female students towards female genital mutilation in Sudan. Eastern Mediterranean health journal $=\mathrm{La}$ revue de sante de la Mediterranean Orientale $=$ al-Majallah al-sihhiyah lisharq al-mutawassit. 2019 Aug 19; 25(6):406-12.

35.Pinar SE, Sabanciogullari S. Nursing and Midwifery Students' Attitudes towards Violence against Women and Recognizing Signs of Violence against Women. International Journal of Caring Sciences. 2019 Sep 1; 12(3). 